\title{
PATIENT CHARACTERISTICS ASSOCIATED WITH NON- ADHERENCE TO ANTI TUBERCULOSIS TREATMENT IN SRI LANKA
}

\author{
KAS Jayawardena, C Sarukkali, AKSB de Alwis, S Samaraweera, D Waidyaratne, S Nawaratne, \\ R Perera, Darmasiri R, A Kariyawasam, RASE Illangakoon, DNK Wijesingha, PM Karunadasa \\ National Programme for Tuberculosis Control and Chest Diseases, Sri Lanka
}

\begin{abstract}
Introduction: Sri Lanka had achieved a significant improvement in the tuberculosis control including a reduction of the default rate since introduction of the DOTS strategy to the National TB control Programme in 1997. Patients' adherence to anti TB treatment may be measured using either process oriented or outcome oriented definitions. Default rate is an outcome oriented definition that may be used as an indicator of poor patient adherence to anti TB treatment. One of the main obstacles in achieving the best tuberculosis (TB) control is that patients do not complete full course of anti TB treatment. A prospective cohort study was carried out with the objective to identify patient characteristics that associate with defaulting anti tuberculosis treatment
\end{abstract}

Methodology: This was a prospective cohort study of new smear positive pulmonary tuberculosis patients registered for treatment between 1.6.2008 and 31.8.2008 in seven districts in Sri Lanka. Data on the patient characteristics and the plan of management were collected at the beginning of the treatment using a pre tested structured questionnaire. During the follow up and at the end of the treatment, results of sputum microscopy and the treatment outcome were recorded. The patients who interrupted treatment for 2 months or more (defaulters) during the course of treatment were again investigated in the field. In the statistical analysis, patient characteristics of the defaulters were compared with the characteristics of patients who were cured.

Results: There were 22 defaulters giving a default rate of $4.59 \%$. Being a male, poor educational background, having a casual job, regular smoking, and regular alcohol use were significantly associated with defaulting treatment $(p<0.05)$. Sinhalese had lower default rate than other ethnic groups. At the field investigation, $43 \%$ of the defaulters were found not living in the addresses given to the treatment providers. Field investigators have further reported that financial reasons, substance abuse, feeling well, and lack of family support also as causes of defaulting treatment.

Conclusion: Identification of risk factors by careful patient interview, early home visit, and monitoring of patient behaviour early in the course of treatment will help to predict whether adherence is likely to be a problem. So that, the treatment provider will be able to arrange a flexible and patient centered approach to ensure maximum adherence.

Key words: Non-adherence, Anti-TB Treatment, Sri Lanka

\section{INTRODUCTION}

Patients' adherence to anti TB treatment may be measured using either process oriented or outcome

Correspondence:
Dr. K.A.S. Jayawardena
National Programme for Tuberculosis Control and Chest
Diseases
555/5, Elvitigala Mawatha, Narahenpita
Colombo 5, Sri Lanka
Email: kasjaya60@yahoo.com

oriented definitions. ${ }^{1}$ Default rate is an outcome oriented definition that may be used as an indicator of poor patient adherence to anti TB treatment. One of the main obstacles in achieving the best tuberculosis (TB) control is that patients do not complete full course of anti TB treatment. Review of annual reports of the National Programme for TB Control in Sri Lanka since year 2000 to 2008 reveals that default rate accounted for a large proportion of unfavourable treatment outcomes in any category of tuberculosis patients registered 
for anti TB treatment. Non-adherence to correct treatment increases the risk of spreading the TB infection in the community and development of drug resistance in the patient. ${ }^{2}$

Sri Lanka had achieved a significant improvement in the tuberculosis control including a reduction of the default rate since introduction of the DOTS strategy to the national TB control programme in 1997. The default rate of 14.8 among new smear positive pulmonary TB patients registered in the year 2000 was gradually reduced up to 6.2 among those registered in $2005 .^{3,4}$ In the same category of patients the cure rate increased from 74.9 to 82.9 during the same period. The Fixed Dose Combination (FDC) chemotherapy was then introduced in 2005 to simplify administration of drugs and to improve the patient adherence to correct treatment regimen. FDC drugs too are said to be a quality combination of anti TB drugs. However, annual statistics of the national programme in subsequent years did not indicate a significant improvement of treatment success including reduction of default rate (Table 1). Reasons for non progression of treatment success may be multifactorial including patients continue to interrupt anti TB treatment.

\begin{tabular}{|c|c|c|c|}
\hline Year & $\begin{array}{c}\text { Total number } \\
\text { registered }\end{array}$ & Cure rate & Default rate \\
\hline 2000 & 4314 & 74.9 & 14.8 \\
\hline 2001 & 4316 & 77.0 & 13.2 \\
\hline 2002 & 4297 & 77.5 & 12.1 \\
\hline 2003 & 3652 & 77.7 & 10.6 \\
\hline 2004 & 4302 & 81.6 & 8.4 \\
\hline 2005 & 4841 & 82.9 & 6.2 \\
\hline 2006 & 4431 & 83.3 & 6.7 \\
\hline 2007 & 4477 & 83.6 & 7.1 \\
\hline
\end{tabular}

Source - National Programme for Tuberculosis Control and Chest Diseases

In practice it is the patient who is frequently blamed for interrupting the treatment. Literature review reveals that factors associated with adhering to anti TB treatment are multiple. These factors include patient characteristics, the relationship between healthcare provider and patient, social support, cultural influence, the treatment regimen and the health care setting. ${ }^{1,5}$ It is interesting to investigate risk factors for non-adherences in the Sri Lankan context too. The aim of this study was to identify patient characteristics that associate with defaulting anti TB treatment.

\section{METHODOLOGY}

This was a prospective cohort study conducted in seven districts - Anuradhapura, Badulla, Colombo, Galle, Kegalla, Kurunegala, and Nuwara Eliya. The criterion used to select districts for the study was to have a proportionate representation of urban, rural, and estate populations in Sri Lanka in the study sample. All the selected districts had district TB clinics and qualified staff, laboratory facilities, and substantial number of patients attending for anti TB treatment. The study sample comprised of all new smear positive pulmonary tuberculosis patients registered for anti tuberculosis treatment (ATT) between 1.6.2008 and 31.8.2008. Ethical clearance was obtained from the Ethical Review Committee, Faculty of Medicine, University of Peradeniya, Sri Lanka. The patients were recruited for interview after obtaining informed consent to participate in the study.

An interviewer administered pre-tested structured questionnaire was used to collect data. Each patient's demographic profile, smoking, drug abuse and alcohol habits, details of past illnesses, and details of pre-treatment sputum examination results were recorded at the time of starting anti TB treatment. Patients who reported smoking more than 5 cigarettes a day for the last 5 years were considered as regular smokers and patients who reported consuming alcohol at least once a week for the last 6 months were considered as regular drinkers. Persons who have admitted themselves as current drug users (those who inhale or inject narcotic substances at present) were recorded as drug users. During the follow-up, sputum examinations (DS X 2) were done at two, five and six months of treatment. At the end of one year, treatment outcomes of all patients were recorded.

Patients who had been reported as having interrupted treatment continuously for more than 2 months during the course of treatment were identified as defaulters. These patients were 
selected to analyse their personal characteristics that are associated with default. A field investigation was carried out using a check list to find out more information about these defaulters. The check list included a number of items to inquire whether the defaulter had given correct answers at the initial interview, level of the family support, was service provider unsupportive, financial status of the patient, and any other factors that contributed to the defaulting treatment.

Data collection was conducted by a group of trained data collectors under the direct supervision of the District Tuberculosis Control Officers (DTCO) of the respective district chest clinics. Each group comprised of a medical officer, a nursing officer and a field investigator (Public Health Inspector).

Patient characteristics that are associated with defaulting treatment were analyzed using the data collected by the questionnaire. In the statistical analysis, selected variables of defaulters were compared with the same variables of patients who had been reported as cured at the end of six months of treatment. The statistical tests (chi squared tests) were carried out using Minitab 14 statistical software. The $p<0.05$ was considered as statistically significant. Findings of field investigations were summarized at the end of statistical data analysis.

\section{RESULTS}

A total of 462 new smear positive PTB patients had been enrolled from the seven districts during the study period. Four patients were excluded from the sample as they had been in different categories of treatment. Therefore the actual sample size was 458.

\section{Personal characteristics of the patients}

The patients of the sample were aged between 11 and 83 years with a mean of 43.6 years (SD $15.81 Y$ ). Majority of the patients were males (71.62\%). Sinhalese constituted $75.8 \%$ of the entire sample. A majority of the respondents (58.73\%) had studied up to the level of secondary school education while $7.4 \%$ had never gone to school. A majority of the patients $(86.2 \%)$ reported living in the own residence and most of the others were living in a close relative's house. More than $80 \%$ of the patients were identified as economically active (employed, house wives or studying) at the time of diagnosis (Table 2). A majority (79\%) of patients had expressed willingness to attend a local health centre for daily observed treatment while $6 \%$ had strongly refused to do so.

\begin{tabular}{|c|c|c|}
\hline Variable & Number & Percentage \\
\hline \multicolumn{3}{|l|}{ Age (Years) } \\
\hline$<15$ & 04 & 00.87 \\
\hline $16-30$ & 103 & 22.49 \\
\hline $31-45$ & 129 & 28.17 \\
\hline $46-60$ & 162 & 35.37 \\
\hline $61<$ & 60 & 13.10 \\
\hline \multicolumn{3}{|l|}{ Sex } \\
\hline Male & 328 & 71.62 \\
\hline Female & 130 & 28.38 \\
\hline \multicolumn{3}{|l|}{ Ethnicity } \\
\hline Sinhalese & 347 & 75.76 \\
\hline Tamil & 52 & 11.35 \\
\hline Moor & 52 & 11.35 \\
\hline Other & 07 & 01.54 \\
\hline \multicolumn{3}{|c|}{ Highest level of education } \\
\hline Not gone to school & 34 & 07.42 \\
\hline Primary & 143 & 31.22 \\
\hline Secondary & 269 & 58.74 \\
\hline Higher & 12 & 02.62 \\
\hline \multicolumn{3}{|c|}{ Current place of residence } \\
\hline Permanent (own) & 395 & 86.24 \\
\hline Street & 04 & 00.87 \\
\hline Work place & 12 & 02.62 \\
\hline Boarding house & 07 & 01.53 \\
\hline Hostel & 03 & 00.66 \\
\hline Relatives house & 32 & 06.99 \\
\hline Prison & 05 & 01.09 \\
\hline \multicolumn{3}{|l|}{ Occupation } \\
\hline $\begin{array}{l}\text { Permanent employee } \\
\text { in government or } \\
\text { private sector }\end{array}$ & 68 & 14.85 \\
\hline Self employed & 71 & 15.50 \\
\hline Casual labourer & 91 & 19.87 \\
\hline Agricultural worker & 40 & 08.73 \\
\hline Student & 28 & 06.11 \\
\hline \begin{tabular}{|l|} 
House wife \\
\end{tabular} & 74 & 16.16 \\
\hline Retired or other & 53 & 11.57 \\
\hline Un - employed & 33 & 07.20 \\
\hline
\end{tabular}


Nearly one third (31\%) of the sample was identified as regular smokers and one fifth $(20.5 \%)$ of the sample was identified as regular drinkers. A few patients $(3.7 \%)$ had reported as having abused narcotic drugs (Table 3 ). Of the total, none of the female patients were identified as either regular smokers or alcohol and narcotic drug abusers.

\begin{tabular}{|c|c|c|}
\hline Variable & Number & Percentage \\
\hline \multicolumn{3}{|l|}{ Smoking } \\
\hline Regular smoker & 141 & 30.79 \\
\hline Never / occasional & 317 & 69.21 \\
\hline \multicolumn{3}{|l|}{ Alcohol use } \\
\hline Regular drinker & 94 & 20.52 \\
\hline Never / occasional & 364 & 79.48 \\
\hline \multicolumn{3}{|l|}{ Narcotic drug use } \\
\hline Yes & 17 & 3.71 \\
\hline No & 426 & 93.01 \\
\hline Not known & 15 & 03.28 \\
\hline
\end{tabular}

A total of $77(17.9 \%)$ patients had reported as having diabetes mellitus and $25(5.81 \%)$ patients had reported as having chronic respiratory diseases (Table 4). Eighteen patients had reported as having multiple diseases which included diabetes (16), respiratory diseases (3), renal diseases (1), liver disease (1), and other diseases (14) in 2 or more combinations. Grading of the initial bacillary load in sputum samples was recorded in 426 patients and a majority (45.5\%) had one plus (Table 5).

Table 4. Presence of co-morbidity reported by the patients $(n=430)$

\begin{tabular}{|l|c|c|}
\hline Disease & Number & Percentage $^{*}$ \\
\hline Diabetes & 77 & 17.91 \\
\hline Renal diseases & 04 & 00.93 \\
\hline Liver diseases & 01 & 00.23 \\
\hline Cancer & 01 & 00.23 \\
\hline Respiratory diseases & 25 & 05.81 \\
\hline Other & 26 & 06.04 \\
\hline No disease & 313 & 72.79 \\
\hline
\end{tabular}

* Percentages will not add to 100 due to the presence of multiple responses

Table 5. Pre treatment sputum grading $(n=426)$

\begin{tabular}{|l|c|c|}
\hline \multicolumn{1}{|c|}{ Grading } & Number & Percentage \\
\hline Scanty & 24 & 05.64 \\
\hline One plus & 194 & 45.54 \\
\hline Two pluses & 93 & 21.83 \\
\hline Three pluses & 115 & 26.99 \\
\hline
\end{tabular}

Four hundred and thirty six (95\%) patients had been started on ATT under directly observed treatment (DOT). Of them, $84.63 \%$ had been put on daily DOT and the balance had been put on intermittent DOT on regular basis. Five percent had self-administered treatment. For a majority $(67.2 \%)$ of the patients, DOT was arranged only for the intensive phase of the treatment. Government health care workers accounted for $86 \%$ of the DOT supervisors. The remaining $14 \%$ comprised of community volunteers and health workers in the private sector.

Three hundred and seventy eight (82.53\%) patients were reported as cured and 28 patients $(6.11 \%)$ were reported as treatment completed. Thus the overall success rate was $88.64 \%$. A total of $51(11.14 \%)$ patients were found to have had unfavourable treatment outcomes (death, defaulted and treatment failure) (Table 6).

Table 6. Treatment outcome of the sample $(n=458)$

\begin{tabular}{|l|c|c|}
\hline Outcome & Number & Percentage \\
\hline Cured & 378 & 82.53 \\
\hline Treatment completed & 28 & 06.11 \\
\hline Transferred out & 01 & 00.22 \\
\hline Death & 22 & 04.80 \\
\hline Defaulted & 21 & 04.59 \\
\hline Failure & 08 & 01.75 \\
\hline Total & 458 & 100.00 \\
\hline
\end{tabular}

Twenty one patients had defaulted treatment, giving a default rate of $4.59 \%$. Among them, 10 $(48 \%)$ had defaulted during the intensive phase of treatment. The Colombo district reported the highest $(7.6 \%)$ default rate. According to the questionnaire all defaulters had been arranged DOTS in government health centres either daily $(80 \%)$ or intermittent $(20 \%)$ basis. Ninety percent of them had voluntarily consented that they could attend the treatment centre daily for treatment.

Of the total of 378 patients who reported as cured we selected those who had converted sputum at the end of the intensive phase of treatment and remained negative at the end of 5 and 6 months. There were 335 such patients. Personal characteristics of those patients were then compared with the defaulters using chi-squared test. Being a male, poor educational background, 
having a casual job, and regular smoking and regular alcohol use were significantly associated with defaulting treatment (Table 7). Ethnic groups other than Sinhalese had relatively higher default rate while age, type of residence, initial sputum grading, and co-morbidity did not show a significant association with defaulting treatment.

The field investigation of defaulters revealed that $9(43 \%)$ of the defaulted patients were not living in the addresses given to the district chest clinic and therefore were untraceable. Among the remaining defaulters, the reasons for default according to the opinions of the field investigators were financial constrains, substance abuse, feeling well, and lack of family support.

\section{DISCUSSION}

Sri Lanka has achieved global targets of case detection and treatment success in 2005. The case detection rate for 2007 was $85.6 \%$ and treatment success for the 2006 cohort of new smear-positive cases was $87 \%{ }^{6}$ However, among the unfavourable treatment outcomes, proportion of default is substantial. ${ }^{6}$ Adhering to daily treatment is not an easy task for a patient or a treatment provider. In this study, 21 patients had defaulted treatment for two months or more giving a default rate of 4.59 . Being a male, being a casual employee, poor educational background, being a regular smoker and regular use of alcohol were significantly associated with defaulting treatment. None of the female patients of the sample had reported regular smoking and alcohol use, and only less than $1 \%$ had reported having casual jobs. These could be the main contributing factors for reporting significantly low default rate among female patients. A relatively higher percentage of patients in minority ethnic groups (Tamil and Moor) had defaulted treatment (Table 7). The place of residence, whether permanent or not, did not show a significant difference in relation to defaulting treatment. However, field investigation revealed that $43 \%$ of defaulted patients were not living in the addresses given to the district chest clinics. But, they all had indicated at the initial interview that they lived in permanent residences.

In a study conducted in Singapore, self-reported reasons for default had been described as financial difficulties, pressure of work, side effects, hospital admission, and physical hardships. ${ }^{7}$ Poor interaction between DOT providers and patients had been demonstrated as a cause of poor treatment adherence in Nepal. ${ }^{8}$ The present study showed that all defaulters had been arranged DOT in government health centres and nearly $50 \%$ of them had defaulted treatment during intensive phase of treatment. Health workers in the state health institutions are the main category of DOT providers in Sri Lanka. We observe that excessive use of state health centre based DOT carries certain disadvantages for patients. For example, some patients have to travel long distances for treatment on daily basis spending more money and experiencing physical hardships. Due to nonflexibility in time in the state health service, patients tend to lose their working time and therefore lose income when they attend for daily DOT. Similar problems of attending DOT centres were also reported in Nepal. ${ }^{9}$ The same study further reported that social stigma attached to the disease, poor patient counseling by treatment providers, and consultation of traditional healers by TB patients also contributed to defaulting treatment. A study conducted in the Kandy district, Sri Lanka investigated the usefulness of recruiting trained family members as DOT providers in selected patients. ${ }^{10}$ The results were encouraging in relation to treatment adherence. According to that study, the important prerequisites to ensure successful family DOT include correct selection of patients and DOT providers, giving adequate instruction for treatment adherence, and regular monitoring of drug intake by home visits.

We observed some limitations of our study. The present study did not systematically investigate the service factors associated with defaulting treatment. However some weaknesses of the service were identified while investigating defaulted patients in the field. For example, a large number of defaulters had not given proper information about their place of residence. This had not been identified by the treatment providers until those patients were investigated in the field for defaulting treatment. The calculated default rate for the study sample was 4.59. According to the 


\begin{tabular}{|c|c|c|c|c|c|c|}
\hline \multirow{2}{*}{ Variables } & \multicolumn{2}{|c|}{ Cured patients } & \multicolumn{2}{|c|}{ Defaulters } & \multirow[t]{2}{*}{$\chi^{2}$} & \multirow[t]{2}{*}{$P$ value } \\
\hline & Number & $\%$ & Number & $\%$ & & \\
\hline \multicolumn{7}{|l|}{ Sex } \\
\hline Male & 233 & 92.46 & 19 & 7.54 & \multirow[t]{2}{*}{4.18} & \multirow[t]{2}{*}{0.04} \\
\hline Female & 102 & 98.07 & 02 & 1.93 & & \\
\hline \multicolumn{7}{|l|}{ Age } \\
\hline$<45$ & 171 & 95.54 & 8 & 4.46 & \multirow[t]{2}{*}{1.32} & \multirow[t]{2}{*}{0.25} \\
\hline$\geq 45$ & 164 & 92.65 & 13 & 7.35 & & \\
\hline \multicolumn{7}{|l|}{ Ethnicity } \\
\hline Sinhalese & 262 & 95.27 & 13 & 4.73 & \multirow[t]{2}{*}{2.98} & \multirow[t]{2}{*}{0.08} \\
\hline Other & 73 & 90.12 & 8 & 9.88 & & \\
\hline \multicolumn{7}{|l|}{ Education } \\
\hline$\leq$ Primary & 109 & 87.20 & 16 & 12.80 & \multirow[t]{2}{*}{16.528} & \multirow{2}{*}{0.000} \\
\hline$\geq$ Secondary & 226 & 97.83 & 05 & 2.17 & & \\
\hline \multicolumn{7}{|l|}{ Residence } \\
\hline Permanent & 289 & 94.13 & 18 & 5.87 & \multirow[t]{2}{*}{0.005} & \multirow[t]{2}{*}{0.943} \\
\hline Other & 46 & 93.87 & 03 & 6.13 & & \\
\hline \multicolumn{7}{|l|}{ Occupation } \\
\hline Permanent & 55 & 96.49 & 02 & 3.51 & \multirow[t]{2}{*}{4.976} & \multirow[t]{2}{*}{0.026} \\
\hline Casual & 60 & 84.51 & 11 & 15.49 & & \\
\hline \multicolumn{7}{|l|}{ Smoking } \\
\hline Regular smoker & 87 & 89.69 & 10 & 10.31 & \multirow[t]{2}{*}{4.67} & \multirow{2}{*}{0.031} \\
\hline Other & 248 & 95.75 & 11 & 4.25 & & \\
\hline \multicolumn{7}{|l|}{ Use of alcohol } \\
\hline Regular drinker & 61 & 85.91 & 10 & 14.09 & \multirow[t]{2}{*}{10.705} & \multirow[t]{2}{*}{0.001} \\
\hline Other & 247 & 96.14 & 11 & 3.86 & & \\
\hline \multicolumn{7}{|c|}{ Initial sputum grading } \\
\hline Scanty \& one plus & 173 & 94.53 & 10 & 5.47 & 0.226 & 0.635 \\
\hline Two \& three pluses & 139 & 93.29 & 10 & 6.71 & & \\
\hline Co- morbidity & & & & & & \\
\hline Reported "yes" & 87 & 96.66 & 3 & 3.34 & 1.56 & 0.212 \\
\hline Reported "no" & 226 & 93.00 & 17 & 7.00 & & \\
\hline
\end{tabular}

annual statistics of the seven districts default rate of same category of patients in the same year was 7.1. One possibility for reporting higher default rate in the annual statistics may be due to miscounting of TB deaths as defaulters without investigating the reason for default. On the other hand health workers of the respective districts may have taken extra precautions to reduce the incidence of premature interruption of treatment by the study sample.

\section{CONCLUSION}

Demographic factors identified as risk factors for defaulting treatment are not amenable to intervention for immediate behaviour change.
Identification of risk factors by careful patient interview, early field investigation (home visit), and monitoring of patient behaviour early in the course of treatment will help to predict whether adherence is likely to be a problem. So that, the treatment provider can plans a flexible patient centered approach to ensure maximum adherence. Service factors that associate with premature interruption of treatment by patients should also be investigated and corrected.

\section{ACKNOWLEDGEMENTS}

This study was funded by the GFATM. We are grateful to the patients who participated in this study. We sincerely thank the staff of the chest 
clinics for collecting data and Dr. Hemantha Herath (consultant community physician, Ministry of Health) for technical advice.

\section{REFERENCES}

1. World Health Organization. Adherence to long term therapies. Evidence for action. Geneva: World Health Organization 2003:123-30.

2. World Health Organization. Treatment of Tuberculosis. Guidelines for national programmes. Geneva: World Health Organization 2003:47-52.

3. National Programme for Tuberculosis Control and Chest Disease. Administration Report 2001. Colombo: Ministry of Health, Sri Lanka.

4. National Programme for Tuberculosis Control and Chest Disease. Annual Report 2006. Colombo: Ministry of Health Sri Lanka.

5. Sumartojo E. When tuberculosis treatment fails. A social behavioral account of patient adherence. American Review of Respiratory Disease 1993;147:1311- 20
6. National Programme for Tuberculosis Control and Chest Disease. Annual Report 2007. Colombo: Ministry of Health Sri Lanka.

7. Chee CBE, Boudville IC, Chan SP, Zee YK, Wang YT. Patient and disease characteristics, and outcome of treatment defaulters from Singapore TB control unit - a one year retrospective survey. Int J Tuberc Lung Dis 2000;4:496-503.

8. Mirsha P, Hasan EH, Sabroe S, Kafle KK. Adherence is associated with the quality of professional - patient interaction in Directly Observed Treatment Short-course, DOTS. Patient Education and Counseling 2006;63:29-37.

9 Lamsal DK, Lewis OD, Smith S, Jha N. Factors related to defaulter and treatment failure of tuberculosis patients in the DOTS program in the Sunsary district of Eastern Nepal. SAARC J Tuber Lung Dis HIVIAIDS 2009; VI:25-30.

10 Jayawardena KAS, Medagedara D. Involving family members in the delivery of TB care in the Kandy district, Sri Lanka. SAARC J Tuber Lung Dis HIVIAIDS 2009; VI:12-15. 